Pacific Journal of Mathematics

ON A THEOREM OF NIKODYM WITH APPLICATIONS TO
WEAK CONVERGENCE AND YON NEWMAN ALGEBRAS 


\title{
ON A THEOREM OF NIKODYM WITH APPLICATIONS TO WEAK CONVERGENCE AND VON NEUMANN ALGEBRAS
}

\author{
R. B. DARST
}

\begin{abstract}
The theorem of the title is a "striking improvement of the principle of uniform boundedness" in the space of countably additive measures on a sigma algebra. It says that if a set $T$ of countably additive measures $\mu$ on a sigma algebra $S$ is pointwise bounded: $\sup _{\mu \in T}|\mu(E)|<\infty, E \in S$, then it is uniformly bounded: $\sup _{\mu \in T}\left(\sup _{E \in S}|\mu(E)|\right)<\infty$.
\end{abstract}

Notice that the content of Nikodym's theorem is not changed by assuming that $T$ is a countable set and recall that a countably additive complex valued measure on a sigma algebra is bounded and finitely additive.

An elementary example is given which illustrates that the theorem can not be extended to the case of bounded and countably additive measures on an algebra of sets. Next the theorem is extended, via a "sliding hump" argument, to the case where the measures are bounded and finitely additive on a sigma algebra. Then, after some remarks concerning weak convergence, the extended theorem is applied to extend recent results of Aarnes for normal functionals on a von Neumann algebra to the general case.

In order to set the notation, let us begin by stating our extension of Nikodym's theorem [4, Th. 8, p. 309-311].

THEOREM. If $\left\{\mu_{n}\right\}$ is a sequence of bounded and finitely additive measures on a sigma algebra $S$ of subsets of a set $X$ such that for each element $E$ of $S \sup _{n}\left|\mu_{n}(E)\right|<\infty$, then $\sup _{n}\left(\sup _{E \in S}\left|\mu_{n}(E)\right|\right)<\infty$.

As mentioned above, before establishing the theorem let us consider the following example. Suppose $X$ is the set of nonnegative integers and a subset $E$ of $X$ is in $S$ if either $E$ or $X-E$ is a finite subset of the positive integers. Let $\left\{\mu_{n}\right\}$ be defined on $S$ by $\mu_{n}(E)=n$ if $E$ is a finite set containing $n, u_{n}(E)=0$ if $E$ is a finite set not containing $n$, and $\mu_{n}(E)=-\mu_{n}(X-E)$. Then $\left\{\mu_{n}\right\}$ is a sequence of bounded and countably additive measures on $S$ satisfying (i) for each $E \in S \lim _{n}\left|\mu_{n}(E)\right|=0$, but also (ii)

$$
\lim _{n}\left(\sup _{E \in S} \mu_{n}(E)\right)=\infty .
$$

Proof of theorem. Suppose on the contrary that

$$
\sup _{n}\left(\sup _{E} \in S\left|\mu_{n}(E)\right|\right)=\infty \text {. }
$$


Observe that this supposition implies that if $p>0$, then there exists a positive integer $n$ and a partition $(E, F)$ of $X$ in $S($ i.e., $(E, F)$ is a pair of pairwise disjoint elements of $S$ such that $E \cup F=X$ ) such that $\min \left(\left|\mu_{n}(E)\right|,\left|\mu_{n}(F)\right|\right)>p$ because if $\left|\mu_{n}(E)\right|>\sup _{k}\left|\mu_{k}(X)\right|+p$, then $\left|\mu_{n}(F)\right| \geqq\left|\mu_{n}(E)\right|-\left|\mu_{n}(X)\right|>p$. Let $n_{1}$ be the least positive integer such that there exists a partition $\left(E_{1}, F_{1}\right)$ of $X$ in $S$ satisfying $\min \left(\left|\mu_{n_{1}}\left(E_{1}\right)\right|,\left|\mu_{n_{1}}\left(F_{1}\right)\right|>2\right.$. At least one of $\sup _{n}\left(\sup _{E \epsilon_{S}} \mu_{n}\left(E \cap E_{1}\right)\right)$ and $\sup _{n}\left(\sup _{E \in S} \mu_{n}\left(E \cap F_{1}\right)\right)$ is infinite; suppose that the former sup is infinite. Now, letting $E_{1}$ play the role of $X$, let $n_{2}$ be the least integer greater than $n_{1}$ such that there exists a partition $\left(E_{2}, F_{2}\right)$ of $E_{1}$ in $S$ for which $\sup _{n}\left(\sup _{E} \in S \mu_{n}\left(E \cap E_{2}\right)\right)=\infty$ and

$$
\left|\mu_{n_{2}}\left(F_{2}\right)\right|>\sup _{n}\left|\mu_{n}\left(F_{1}\right)\right|+3 \text {. }
$$

Iterating this process and relabeling if necessary $\left(n_{k} \rightarrow k\right)$, we obtain a sequence $\left\{F_{k}\right\}$ of pairwise disjoint elements of $S$ such that

$$
\left|\mu_{k}\left(F_{k}\right)\right|>\Sigma_{j<k}\left|\mu_{k}\left(F_{j}\right)\right|+k+1 .
$$

Decomposing, if you wish, $\left\{F_{k}\right\}_{k \geq 2}$ into a sequence of subsequences, it becomes clear that since $\mu_{1}$ is bounded there is a subsequence $\left\{F_{k_{i}}\right\}_{i \geqq 1}$ of $\left\{F_{k}\right\}_{k \leqq 2}$ verifying $\sup _{E \in S}\left|\mu_{1}\left(E \cap\left[\bigcup_{i} F_{k_{i}}\right]\right)\right|<1$. Repeating this process we obtain a subsequence $n_{1}=1, n_{2}=k_{1}, \cdots$ satisfying

$$
\sup _{E \in S}\left|\mu_{n_{j}}\left(E \cap\left[\bigcup_{i>j} F_{n_{i}}\right]\right)\right|<1 .
$$

Finally, invoking now the hypothesis that $S$ is a sigma algebra, let $G=\bigcup_{i} F_{n_{i}}$ and notice that the contradiction

$$
\left|\mu_{n_{i}}(G)\right| \geqq\left|\mu_{n_{i}}\left(F_{n_{i}}\right)\right|-\Sigma_{j<i}\left|\mu_{n_{i}}\left(F_{n_{j}}\right)\right|-\left|\mu_{n_{i}}\left(\mathbf{U}_{j>i} F_{n_{j}}\right)\right|>n_{i}
$$

obtains.

Toward a promised application, suppose that $\lim _{n} \mu_{n}(E)$ exists for $E \in S$. While existence of these limits is a necessary condition for the sequence $\left\{\mu_{n}\right\}$ to converge weakly, our example shows that if $S$ is merely an algebra of sets, then the sequence $\left\{\mu_{n}\right\}$ need not be bounded and, hence, certainly not weakly convergent. Nevertheless, suppose $S$ is a sigma algebra and $\mu(E)=\lim _{n} \mu_{n}(E)$. Then by the Theorem $\mu$ is a bounded and finitely additive measure on $S$ and if $\nu_{n}=\mu_{n}-\mu$, then $\left\{\nu_{n}\right\}$ is a sequence of bounded and finitely additive measures on $S$ satisfying $\lim _{n} \nu_{n}(E)=0, E \in S$. We shall show that the sequence $\left\{\nu_{n}\right\}$ converges weakly to zero. To this end it is sufficient in view of [6, Th. 3.1] (see also [3]) to show that if $\left\{F_{k}\right\}$ is a sequence of pairwise disjoint elements of $S$, then $\lim _{n}\left(\Sigma_{k} \nu_{n}\left(F_{k}\right)\right)=0$ which is an easy consequence of [5, Lemma 3.3] (identity $F_{k}$ with $k$ ). The following corollary is thus established. 
Corollary. A sequence $\left\{\mu_{n}\right\}$ of bounded and finitely additive measures on a sigma algebra $S$ is weakly convergent if, and only if, $\lim _{n} \mu_{n}(E)$ exists, $E \in S$.

REMARK. Alternately, a very short proof of our theorem can be given using weak convergence theory and Phillips' Lemma as in our proof of the corollary: Suppose $\sup _{n}\left|\mu_{n}(E)\right|<\infty, E \in S$, and

$$
\sup _{n}\left(\sup _{E \in S}\left|\mu_{n}(E)\right|\right)=\infty .
$$

Then there exists a subsequence $\left\{\mu_{n_{k}}\right\}$ such that if $\lambda_{k}=1 / k \mu_{n_{k}}$, then $\left\{\lambda_{k}\right\}$ satisfies $\lim _{k}\left|\lambda_{k}(E)\right|=0, E \in S$, (which implies weak convergence and, hence, boundedness) and the contradictory condition

$$
\lim _{k}\left(\sup _{E \in S}\left|\lambda_{k}(E)\right|\right)=\infty .
$$

It should also be noted that Andô [2] recognized the role of Phillips' Lemma and pointwise convergence in the general case.

Turning now to Aarnes results, we refer the reader to [1] for a discussion of the setting and restrict our attention to a sketch of the technical modifications which are necessary to establish the following theorems.

THEOREM 1'. If $\mathfrak{F}$ is a family of functionals on a von Neumann algebra $\mathfrak{A}$, which is pointwise bounded on the projections in $\mathfrak{A}$, then $\mathfrak{F}$ is uniformly bounded on bounded sets of $\mathfrak{A}$.

Proof. Let $A$ be a self-adjoint operator in a von Neumann algebra $\mathfrak{A}$, and let $\mathfrak{B}$ be the commutative von Neumann sub-algebra of $\mathfrak{U}$ it generates. Suppose now that $\mathfrak{F}$ is a family of linear functionals on $\mathfrak{U}$ which is pointwise bounded on the projections in $\mathfrak{A}$. A fortiori $\mathfrak{F}$ is then pointwise bounded on the projections in $\mathfrak{B}$.

By the representation of $\mathfrak{B}$ as $L_{C}^{\infty}(S, \mu)$ for some $S$ and $\mu$, this transfers to the statement that for each measurable set $E \subseteq S$ there is a constant $K(E)<\infty$ such that

$$
|\widetilde{\varphi}(E)|<K(E)
$$

for all $\tilde{\varphi} \in b a\left(S, \Sigma_{1}, \mu_{1}\right)$ corresponding to members of $\mathfrak{F}[4$, Ch IV, 8.16, p. 296]. Then it follows, by our Theorem that we can find a constant $K<\infty$ such that

$$
|\tilde{\varphi}(E)|<K
$$

for all measurable sets $E$ in $S$ and the same class of functions $\{\tilde{\varphi}\}$ It immediately follows that the norms of the elements of $\{\widetilde{\varphi}\}$ must 
be uniformly bounded. Hence, by the isometric character of the map $\varphi \rightarrow \widetilde{\varphi}$ we obtain in particular that the set $\{\varphi(A) ; \varphi \in \widetilde{F}\}$ is bounded. But then, by the Banach-Steinhaus theorem and the fact that every operator in $\mathfrak{A}$ can be written as the linear sum of two self-adjoint operators, it follows that $\mathfrak{F}$ is uniformly bounded on bounded sets in $\mathfrak{A}$.

In order to make our concluding remarks comprehensible, let's first state Aarnes' Theorem 2.

THEOREM 2. Let $\left\{\varphi_{n}\right\}_{n \in N}$ be a sequence of normal linear functionals on $\mathfrak{A}$, and suppose that for every projection $P \in \mathfrak{A}, \lim _{n \rightarrow \infty} \varphi_{n}(P)$ exists as a finite complex number, which we denote by $\varphi(P)$. Then:

(i) $\varphi$ has a unique extension to all of $\mathfrak{A}$ as an element of $\mathfrak{H}^{*}$, and $\lim \varphi_{n}(A)$ exists and is equal to $\varphi(A)$ for every $A \in \mathfrak{A}$.

(ii) $\varphi$ is completely additive, and consequently normal.

(iii) The restrictions $\left\{\Phi_{n} \mid \mathfrak{P} \cap \mathfrak{B}\right\}_{n} \in_{N}$ is equicontinuous in 0 with respect to the relativized weak operator topology on any commutative von Neumann sub-algebra $\mathfrak{B} \subseteq \mathfrak{A}$.

(iv) The family $\left\{\varphi_{n}\right\}_{n} \in_{N}$ is uniformly completely additive.

Because the measures $\widetilde{\varphi}_{n}$ need not be countably additive unless the functionals $\varphi_{n}$ are normal (see discussion in [1]), (ii) and (iv) can't be expected to carry over. However, the proof of (i) as given in [1] carries over if Theorem $1^{\prime}$ is used instead of Aarnes' Theorem 1 and (iii) follows from the weak convergence theory for finitely additive measures on a sigma algebra. Thus the following obtains.

THEOREM 2'. Let $\left\{\varphi_{n}\right\}_{n \in N}$ be a sequence of linear functionals on $\mathfrak{A}$, and suppose that for every projection $P \in \mathfrak{A}, \lim _{n \rightarrow \infty} \varphi_{n}(P)$ exists as a finite complex number, which we denote by $\varphi(P)$. Then:

(i ) $\varphi$ has a unique extension to all of $\mathfrak{A}$ as an element of $\mathfrak{U}^{*}$, and $\lim \varphi_{n}(A)$ exists and is equal to $\varphi(A)$ for every $\mathrm{A} \in \mathfrak{A}$.

(ii) The restrictions $\left\{\varphi_{n} \mid \mathfrak{P} \cap \mathfrak{B}\right\}_{n} \in_{N}$ is equicontinuous in 0 with respect to the relativized weak operator topology on any commutative von Neumann sub-algebra $\mathfrak{B} \subseteq \mathfrak{A}$.

\section{BIBLIOGRAPHY}

1. J. Aarnes, The Vitali-Hahn-Saks theorem for von-Neumann algebras, Math. Scand. 18 (1966), 87-92.

2. T. Andô, Convergent sequences of finitely additive measures, Pacific J. Math. 11 (1961), 395-404.

3. R. B. Darst, $A$ direct proof of Porcelli's condition for weak convergence, Proc. Amer. Math. Soc. 17 (1966), 1094-1096.

4. N. Dunford and J. T. Schwartz, Linear Operators, Vol. I, Interscience, 1958, New York. 
5. R. S. Phillips, On linear transformations, Trans. Amer. Math. Soc. 48 (1940), 516-541.

6. P. Porcelli, Two embedding theorems with applications to weak convergence and weak compactness in spaces of additive type functions, J. Math. and Mech. 9 (1960), 273-292.

Received March 22, 1967. The author is partially supported by a National Science Foundation grant.

\section{PuRdue University}





\section{PACIFIC JOURNAL OF MATHEMATICS}

\section{H. ROYDEN}

Stanford University

Stanford, California

\author{
J. P. JANS \\ University of Washington \\ Seattle, Washington 98105
}

\section{EDITORS}

\author{
J. DugundJI \\ Department of Mathematics \\ Rice University \\ Houston, Texas 77001 \\ Richard ARENS \\ University of California \\ Los Angeles, California 90024
}

\section{ASSOCIATE EDITORS}
E. F. BECKENBACH
B. H. NeumanN
F. WOLF
K. YOSIDA

\section{SUPPORTING INSTITUTIONS}

\author{
UNIVERSITY OF BRITISH COLUMBIA \\ CALIFORNIA INSTITUTE OF TECHNOLOGY \\ UNIVERSITY OF CALIFORNIA \\ MONTANA STATE UNIVERSITY \\ UNIVERSITY OF NEVADA \\ NEW MEXICO STATE UNIVERSITY \\ OREGON STATE UNIVERSITY \\ UNIVERSITY OF OREGON \\ OSAKA UNIVERSITY \\ UNIVERSITY OF SOUTHERN CALIFORNIA
}

\author{
STANFORD UNIVERSITY \\ UNIVERSITY OF TOKYO \\ UNIVERSITY OF UTAH \\ WASHINGTON STATE UNIVERSITY \\ UNIVERSITY OF WASHINGTON \\ AMERICAN MATHEMATICAL SOCIETY \\ CHEVRON RESEARCH CORPORATION \\ TRW SYSTEMS \\ NAVAL ORDNANCE TEST STATION
}

Mathematical papers intended for publication in the Pacific Journal of Mathematics should be typewritten (double spaced). The first paragraph or two must be capable of being used separately as a synopsis of the entire paper. It should not contain references to the bibliography. Manuscripts may be sent to any one of the four editors. All other communications to the editors should be addressed to the managing editor, Richard Arens at the University of California, Los Angeles, California 90024.

50 reprints per author of each article are furnished free of charge; additional copies may be obtained at cost in multiples of 50 .

The Pacific Journal of Mathematics is published monthly. Effective with Volume 16 the price per volume (3 numbers) is $\$ 8.00$; single issues, $\$ 3.00$. Special price for current issues to individual faculty members of supporting institutions and to individual members of the American Mathematical Society: $\$ 4.00$ per volume; single issues $\$ 1.50$. Back numbers are available.

Subscriptions, orders for back numbers, and changes of address should be sent to Pacific Journal of Mathematics, 103 Highland Boulevard, Berkeley 8, California.

Printed at Kokusai Bunken Insatsusha (International Academic Printing Co., Ltd.), 7-17, Fujimi 2-chome, Chiyoda-ku, Tokyo, Japan.

PUBLISHED BY PACIFIC JOURNAL OF MATHEMATICS, A NON-PROFIT CORPORATION

The Supporting Institutions listed above contribute to the cost of publication of this Journal, but they are not owners or publishers and have no responsibility for its content or policies. 


\section{Pacific Journal of Mathematics}

A. A. Aucoin, Diophantine systems ............................. 419

Charles Ballantine, Products of positive definite matrices. I ............... 427

David Wilmot Barnette, A necessary condition for d-polyhedrality ............ 435

James Clark Beidleman and Tae Kun Seo, Generalized Frattini subgroups of finite groups ......................................... 441

Carlos Jorge Do Rego Borges, A study of multivalued functions ............. 451

William Edwin Clark, Algebras of global dimension one with a finite ideal

lattice ...............................................

Richard Brian Darst, On a theorem of Nikodym with applications to weak convergence and von Neumann algebras .........................

George Wesley Day, Superatomic Boolean algebras .....................

Lawrence Fearnley, Characterization of the continuous images of all

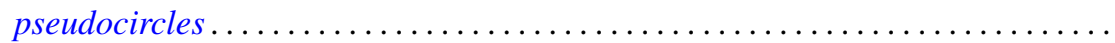

Neil Robert Gray, Unstable points in the hyperspace of connected subsets....... 515

Franklin Haimo, Polynomials in central endomorphisms .................. 521

John Sollion Hsia, Integral equivalence of vectors over local modular lattices . . . . 527

Jim Humphreys, Existence of Levi factors in certain algebraic groups .......... 543

E. Christopher Lance, Automorphisms of postliminal $C^{*}$-algebras ............ 547

Sibe Mardesic, Images of ordered compacta are locally peripherally metric . . . . 557

Albert W. Marshall, David William Walkup and Roger Jean-Baptiste Robert Wets,

Order-preserving functions: Applications to majorization and order

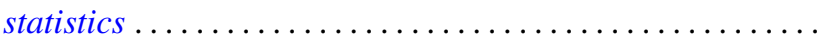

Wellington Ham Ow, An extremal length criterion for the parabolicity of

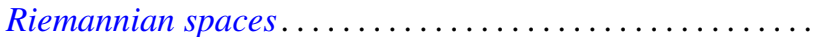

585

Wellington Ham Ow, Criteria for zero capacity of ideal boundary components of

Riemannian spaces...................................... 591

J. H. Reed, Inverse limits of indecomposable continua .................. 597

Joseph Gail Stampfli, Minimal range theorems for operators with thin spectra . . . 601

Roy Westwick, Transformations on tensor spaces..................... 613

Howard Henry Wicke, The regular open continuous images of complete metric

spaces ........................................... 621

Abraham Zaks, A note on semi-primary hereditary rings .............. 627

Thomas William Hungerford, Correction to: "A description of $\operatorname{Mult}_{i}\left(A^{1}, \cdots, A^{n}\right)$

by generators and relations" ............................. 629

Uppuluri V. Ramamohana Rao, Correction to: "On a stronger version of Wallis' formula".............................................. 629

Takesi Isiwata, Correction: "Mappings and spaces" ................... 630

Henry B. Mann, Josephine Mitchell and Lowell Schoenfeld, Correction to:

"Properties of differential forms in $n$ real variables" .... . .

James Calvert, Correction to: "An integral inequality with applications to the

Dirichlet problem"............................. 